\title{
Liberalizing Trade and Capital Flows and the Wage Gap: Does Sequencing Matter?
}

\author{
Rashmi Ahuja ${ }^{1} \cdot$ Sugata Marjit ${ }^{2}$
}

Accepted: 1 September 2021 / Published online: 6 November 2021

(c) The Author(s), under exclusive licence to Springer Science+Business Media, LLC, part of Springer Nature 2021

\begin{abstract}
We consider a small open developing economy with presence of both final and intermediate goods where we analyze the impact of liberalizing trade and capital flows on wage inequality when such policies are undertaken in a sequence. Our findings suggest that when skilled sector is capital intensive relative to the unskilled sector, wage gap always increases independent of the sequence of reforms, but the extent of such increase may vary according to the chosen sequence. However, when unskilled intensive sector is more capital intensive, the impact of these reforms on skilledunskilled wage gap is ambiguous. Later we also demonstrate the robustness of our results to alternative assumptions on the structure of the model.
\end{abstract}

Keywords Skilled-unskilled wage inequality · Foreign capital inflows · Trade liberalization $\cdot$ Sequencing

\section{Introduction}

The purpose of this paper is to show that in a small developing economy trading both final and intermediate goods, technological characteristics of skilled and unskilled labor-intensive goods critically determine the qualitative impact of sequencing trade and capital market reforms on the wage gap, although the quantitative responses can be different. Capital intensity of these goods are critical for the impact on wage gap when we consider capital market reform. If we neutralize that or assume that the skilled sector is capital intensive, sequence of reforms does not matter for the directional change in the wage gap but the magnitude does get affected.

Rashmi Ahuja

rahuja2012@gmail.com

Sugata Marjit

marjit@gmail.com

1 Lal Bahadur Shastri Institute of Management (LBSIM), Delhi, India

2 Indian Institute of Foreign Trade, Kolkata, India 
By sequencing of trade and capital account liberalization, we refer to the order in which these reforms are introduced in any economy. It has been observed that many developing and emerging economies face challenges regarding the appropriate order in which trade and capital account should be liberalized.

For the earlier literature one may look at Diaz-Alejandro (1981), Mckinon (1982), Edwards (1984), Bruno (1985) etc. for discussions on this issue. It has been observed that different economies have approached this issue of order of trade and capital account liberalization in different manner. On the one hand, there are many developing economies (for eg. India, Brazil, China, Chile, Philippines, Bangladesh, Mexico and Thailand) that have liberalized trade first by lowering the trade barriers and then opened their capital account for foreign capital inflows. On the other hand, there also exist some economies like Argentina, Indonesia and Uruguay that have opened the capital account first and then opened trade account by lowering the trade barriers. The underlying idea of this paper is that in these two kinds of economies, the impact of trade and foreign capital inflows on wage inequality will be different and depends on the order in which these reforms are undertaken.

It is important to recognize here that temporal differences in reforms could be a reaction to the existing economic situation. However, it is to be noted that even if it is the economic compulsion that determines sequencing of reforms, it does not take away anything from our results because whatever be the compulsion and the background of the policy decision if there is a sequencing involved and the model is specified as ours, one must confront these results. While the main driver can be something else, groups of countries do demonstrate a pattern of sequencing. But rising wage gap has become a world-wide phenomenon. Our study clearly showed the possibility of such a case and other results with sequencing and simultaneous adoption of policies.

Economists have already contributed to the understanding of the impacts of trade and capital account liberalization reforms on wage gap in various countries. There have been many empirical studies such as Vallejos and Turnovsky (2017), Mishra \& Das (2013), Wu and Hsu (2012), Goldberg and Pavcnik (2007), Winters et al. (2004), Lundberg and Squire (2003) etc. Furceri \& Loungani (2015) shows that capital account liberalization increases the inequality and reduces the labor share in medium and short-term using the panel data for 149 countries for the period 1970-2010. Larrain (2015) also found that capital account opening increases wage inequality in a sample of 20 primarily European countries from 1975 through 2005. But hardly one would find a paper that looks at the sequence of reforms in trade theoretic context.

Theoretically various papers have looked at the issue of trade, immigration and capital market reforms for developing countries but not really at the sequence of reforms and wage gap as we model in this paper. As a sample one may look at, Feenstra and Hanson (1995), Marjit and Acharyaa (2003), Marjit et al. (2007a, b), Hellier (2019), Marjit and Kar (2005, 2019), Mandal and Prasad ${ }^{1}$ (2019), Marjit

\footnotetext{
1 Mandal B, Prasad AS (2019) "A Note on wage inequality due to trade reform, capital inflow, bureaucratic reform and time zone difference", Unpublished manuscript.
} 
et al. (2020), Das et al. (2020) etc. Studies like Dinopoulos et al (2011), Whang (2016) and Burstein and Vogel (2017) in the literature have looked at the impact of intra-industry trade and trade liberalization on the skill premium and output of the firms. However, it is important to note that none of the studies have looked at the impact of sequencing of reforms on skilled-unskilled wage gap as we have modelled in this paper.

We start by developing a two-sector general equilibrium model of a small open developing economy. In such an economy, the unskilled goods are imported and skilled goods are exported. This country also imports an intermediate good that it uses for the import competing skilled sector. The trade pattern, where skilled goods are exported by developing economies, have been motivated from the idea that exports from the developing word do depend on skills. Matsuyama (2007) using model of "skilled-bias globalization" discusses why export destinations may require varying levels of skills. Also, Brambilla et al. (2012) and Chaudhuri \& Marjit (2017) discuss various mechanisms of how exports from developing countries become more skilled as they open up for trade. The latter paper shows how exports can necessitate screening of workers with heterogeneous skills. For an example, one could also look at software services exported by India or exports of machinery and transport equipment's in China's export basket.. ${ }^{2}$ We examine the net impact of the external reforms w.r.t trade and foreign capital inflows on wage inequality under the three sequencing scenarios - i) Trade liberalization precedes capital account liberalization ii) Capital account liberalization precedes trade liberalization and iii) Simultaneous trade and capital account liberalization.

Our findings differ from the study by Dinopoulos et al. (2011) in the following manner. Firstly, they have discussed the effect of movement from autarky to free trade on output and skill premium in intra-industry trade model with Chamberlinian mechanism of income distribution with internal economies of scale, product differentiation, and free entry and exit. However, our model considered two sector three factor model with presence of intermediate goods in the presence of perfect competition and examined the impact of not just movement from autarky to free trade instead the impact of sequencing of both capital account and trade liberalization reforms. Secondly, their findings suggest that the intra-industry trade leads to increase in output of the representative firms and further output-skill complementarity or substitutability decides the impact on skill premium. Moreover, their model is based on Chamberlinian mechanism which operates through changes in each firm's output, so their findings were found to be relevant for both the home and foreign country. Our model has considered only the small open developing economy and the findings from our study emphasizes that technological characteristics of skilled and unskilled labor-intensive goods decides the qualitative impact of sequencing of capital account and trade liberalization reforms whereas the quantitative responses can be different.

\footnotetext{
2 Nataraj and Tandan (2011) found that post-2001 China's exports have diversified. Based on the competitiveness analysis, their findings suggest that the share of hi-tech manufactures has increased while the share of unskilled labor-intensive products in the Chinese exports has gone down during 2001-2006.
} 
Similarly, Burstein and Vogel (2017) found that the trade liberalization increases the skill premium to increase by considering a multi-country quantitative trade model that extends the standard $\mathrm{H}-\mathrm{O}$ model with heterogeneity in productivity across firms within sectors. Again, this study has just focused on the impact of trade liberalization in a parametrized model of 60 countries unlike our study which have focused on the impact of sequencing of trade and capital account reforms on skilledunskilled wage inequality both qualitatively and quantitatively. Our paper identified the pattern of sequencing very clearly which is the motivation of our study. We show that sequencing may not matter if the skilled sector is more capital intensive. Trade or Capital account policy both lead to the same outcome. The insights from our findings could be useful for the underdeveloped countries which are still in the process of liberalization to better understand how they should sequence their trade and capital account reforms so that skilled-unskilled wage gap should not widen. Our approach and the result have not been discussed in the literature. The main contribution of our paper is that whatever be the pattern of sequencing, wage gap must rise if skilled sector is $\mathrm{K}$ - intensive.

Remaining paper is arranged as follows. Section 2 develops the Model with two sectors in the presence of an intermediate good. It has one subsection. Subsection 2.1 discusses the impact of order of reforms w.r.t trade and FDI on wage inequality. Section 3 discusses the robustness of the theoretical framework through model variations. The last section winds up the paper with the concluding remarks. Mathematical calculations are, however, relegated to the appendix.

\section{Model}

In this section, we consider a two-sector model for a perfectly competitive small open economy. Sector $\mathrm{X}$ produces goods using unskilled labor and capital. Sector $\mathrm{Y}$ produces good using skilled labor, capital and an intermediate good, M. The intermediate input, $\mathrm{M}$ could be seen as a collection of foreign technology-embedded inputs (e.g., Computers, data storage units, output devices, automatic data processing machines etc.). For instance, Sector X could be assumed to be an unskilled manufacturing or industrial sector and Sector Y could be assumed to be producing software services with skilled labor, capital and Computers being used as intermediate Good. We could also even think of sector $\mathrm{X}$ as an agriculture sector and Sector $\mathrm{Y}$ as an industrial good being produced by means of capital, skilled labor, and an intermediate input in the form of Raw material.

The intermediate good $\mathrm{M}$ is not produced in the economy and is imported from the world economy at a given price. The trade pattern assumed is such that goods produced in sector $\mathrm{X}$ are imported while those in Sector $\mathrm{Y}$ are exported. It is assumed that there is a uniform tariff ' $\mathrm{t}$ ' on imports of goods produced in sector $\mathrm{X}$ as well as intermediate goods imported. It is assumed that intermediate imports are required in fixed proportion in this economy.

The system follows standard neoclassical assumptions like constant returns to scale, diminishing returns to factor inputs etc. To build the system of equations, we use the following notations:- 
$a_{i j}$ : quantity of factor $\mathrm{i}$ required per unit of output of sector $\mathrm{j} ; \mathrm{i}=\mathrm{L}, \mathrm{S}, \mathrm{K}, \mathrm{M}$ and $\mathrm{j}=\mathrm{X}, \mathrm{Y}$.

$\left(\mathrm{w}, w_{s}\right)$ : unskilled wages and skilled wages.

r: return to capital.

$\mathrm{t}$ : tariff on imports of $\mathrm{Y}$ and intermediate $\operatorname{good} \mathrm{M}$.

$\left(\overline{P_{X}}, \overline{P_{Y}}\right)$ : world price of goods produced in Sector $\mathrm{X}$ and $\mathrm{Y}$;

$\bar{K}$ : Fixed endowment of total capital stock in the economy which consists of both domestic $\left(K_{D}\right)$ and foreign stock $\left(K_{F}\right)$ of capital.

$\sigma_{K}^{i j}$ denotes the elasticity of substitution between factor $\mathrm{i}$ and $\mathrm{j}$ in sector $\mathrm{K}$.

$(\bar{L}, \bar{S})$ : fixed endowment of unskilled labor and skilled labor in the economy.

$\theta_{j i}$ : distributive share of factor $\mathrm{j}$ in sector $\mathrm{i}, \mathrm{j}=\mathrm{L}, \mathrm{S}, \mathrm{K} ; \mathrm{i}=\mathrm{X}, \mathrm{Y}$.

$\lambda_{j i}$ : Proportion of $\mathrm{j}^{\text {th }}$ input employed in $\mathrm{i}^{\text {th }}$ sector for $\mathrm{j}=\mathrm{L}, \mathrm{S}, \mathrm{K}$ in $\mathrm{i}=\mathrm{X}, \mathrm{Y}$;

$\wedge$ denotes the proportional change;

Competitive price conditions imply

$$
\begin{gathered}
a_{L X} w+a_{K X} r=\overline{P_{x}}(1+t) \\
a_{S Y} w_{s}+a_{K Y} r+a_{M Y} \overline{P_{m}}(1+t)=\overline{P_{y}}
\end{gathered}
$$

Full utilization of unskilled labor, skilled labor and capital, respectively, imply,

$$
\begin{gathered}
a_{L X} X=\bar{L} \\
a_{S Y} Y=\bar{S} \\
a_{K X} X+a_{K Y} Y=\bar{K}
\end{gathered}
$$

Demand-supply conditions for intermediate good imply

$$
a_{M Y} Y=M^{*}
$$

Since there are six equations and six unknowns, $w, w_{s}, r, X, Y, M^{*}$, the model is closed and determinate. The exogenous variables are: $\bar{L}, \bar{S}, \bar{K}, t, \overline{P_{x}}, \overline{P_{y}}, \overline{P_{m}}$. This is a variation of the basic specific factor model of Jones $(1965,1971)$.

\subsection{Effect of Sequencing on Wage Inequality in Model}

In this section, we consider a relatively closed economy with restrictions to begin with on both trade and capital account. Now, suppose this economy decides to implement external reforms with respect to both trade and capital account. As discussed, there can be three possibilities w.r.t. sequencing of trade and foreign capital reforms: -

i) Full capital account liberalization precedes trade liberalization

ii) Trade liberalization precedes full capital account liberalization 
iii) Simultaneous trade and Full capital account liberalization.

Our aim is to capture the net impact on skilled-unskilled wage inequality in an economy under the above three sequencing scenarios. Then, further, we examine whether this impact is different or not.

So, we have considered three different cases with respect to trade and capital account liberalization in order to capture the alternate sequencing of trade and capital account liberalization. The three cases considered are: -

CASE 1: Full capital Account liberalization with restrictions on trade: This is the case where the economy undertakes full capital account liberalization by removing the barriers to entry of foreign capital. Full capital account liberalization leads to inflow of more foreign capital into the economy i.e. $\widehat{\bar{K}}>0$. However, the trade restrictions are still maintained which implies that $\widehat{t}=0$.

Differentiating the Eqs. (1)-(6) following Jones (1971), we obtained the comparative static equations (Refer Appendix A for detailed calculations). Then these comparative static equations are solved to get the expression for skilled-unskilled wage inequality as follows: -

$$
\left(\widehat{w}_{s}-\widehat{w}\right)=\frac{\widehat{\bar{K}}}{|\Delta|}\left(\theta_{K X} \theta_{S Y}-\theta_{K Y} \theta_{L X}\right)+\frac{\widehat{t} T}{|\Delta|}\left(\lambda_{K X} \sigma_{X}+\sigma_{Y}^{S K} \lambda_{K Y}\right)
$$

Next, we consider what happens in this case when $\widehat{\bar{K}}>0$ and $\hat{t}=0$. We have,

$\left(\widehat{w}_{s}-\widehat{w}\right)>0$ if $\frac{\theta_{K Y}}{\theta_{S Y}}>\frac{\theta_{K X}}{\theta_{L X}}$, whereas

$\left(\widehat{w_{s}}-\widehat{w}\right)<0$ if $\frac{\theta_{K X}}{\theta_{L X}}>\frac{\theta_{K Y}}{\theta_{S Y}}$ Since $|\Delta|<0$.

Based on the above equations we can state Lemma 1.

Lemma 1 Given the set-up of such an economy, an increase in foreign capital inflow, following capital account liberalization will,

i) increase the skilled-unskilled wage gap i.e. $\left(\widehat{w_{s}}-\widehat{w}\right)>0$ if $\frac{\theta_{K X}}{\theta_{L X}}<\frac{\theta_{K Y}}{\theta_{S Y}}$

ii) decrease the skilled-unskilled wage gap i.e. $\left(\widehat{w_{s}}-\widehat{w}\right)<0$ if $\frac{\theta_{K X}}{\theta_{L X}}>\frac{\theta_{K Y}}{\theta_{S Y}}$

Proof See Appendix.

The intuitive explanation of the above Lemma can be explained as follows.

As the $r$, the cost of capital falls, if skilled sector saves such costs more, then the wage gap increases and if the unskilled sector saves more, then the wage gap decreases. Use of intensity difference on wage gap has been used in a different context by Marjit and Kar (2005) and Anwar (2013).

CASE 2: Trade liberalization with restrictions on capital account $^{3}$ : This is the case where we consider that economy undertakes trade liberalization by reducing

\footnotetext{
3 Implies that there are barriers to foreign capital inflows.
} 
the import tariffs i.e. $\hat{t}<0$. The restrictions on foreign capital inflow are maintained as it is which implies that $\widehat{\bar{K}}=0$.

We consider our expression for skilled-unskilled wage gap from Eq. (7), and examine what happens when $\hat{t}<0$ and $\hat{\bar{K}}=0$.

With $\hat{t}<0,\left(\widehat{w}_{s}-\widehat{w}\right)>0$.

Based on the above calculations, we can state our next Lemma as follows.

Lemma 2 Given the set-up of such an economy, with trade liberalization, the skilled-unskilled wage gap increases i.e. $\left(\widehat{w}_{s}-\widehat{w}\right)>0$.

Proof See Appendix.

With decrease in $t$, the unskilled wage suffers as price of $X$ falls and the skilled wage goes up as the price of the intermediate falls and cost of producing $X$ goes down.

Suppose now we sequence the liberalization policies either way i.e., capital market policy preceding the trade policy or the other way round. Then we have the following proposition.

Proposition 1 Whatever be the sequencing or order of the reform, skilled unskilled wage gap will rise if the skilled sector is capital intensive.

Proof Follows from Lemma 1 and 2.

If skilled sector is capital intensive, whichever reform we choose first wage gap will rise as explained above. If unskilled sector is capital intensive and we start with capital market reform, wage gap will fall but if we choose to reduce t first, wage gap will rise. Here sequencing will matter.

Sequencing definitely becomes critical when the extent of variation in the wage gap is the main concern. Let's take the case when skilled sector is capital intensive so sequencing does not matter in terms of the direction in the movement of the wage gap and wage gap increases.

Let us undertake capital account reform, but suppose that the factor shares though different are really very close, so the wage gap will rise very little as it is directly proportional to ratios of factor shares. Now, with trade reform a drop in $\mathrm{t}$ will increase skilled wage and reduce unskilled wage increasing the wage gap.

If we started with trade reform, by the same drop in t, again skilled wage will rise and unskilled wage will fall, but both responses will be different from when trade reform come second. The cost of capital, $r$ will still be floating unattached to the international rate and unskilled wage will fall more and skilled wage will rise more as capital will leave sector X for Y. Thus, for different sequencing, the magnitude of the wage gap will be different.

The critical point is that if trade reform is initiated first, we shall be in a Specific -Factor world, thus wage gap will be magnified as $\mathrm{K}$ leaves $\mathrm{X}$ for $\mathrm{Y}$. That will be less when $r$ is already frozen due to capital market reforms. But if factor intensities 
are far apart, capital account reform can generate wider wage gap. But for different parametric configurations, the gap can increase by wide margin or narrow margin, the gap will rise.

We can now write up the following proposition.

Proposition 2 Suppose factor shares of skilled and unskilled sector are exactly identical (i.e., $\frac{\theta_{K X}}{\theta_{L X}}=\frac{\theta_{K Y}}{\theta_{S Y}}$ ) then trade reform-capital account reform sequence will lead to higher wage gap than capital account-trade reform sequence.

Proof It can be followed from the specific factor model (See Appendix B) that before capital mobility wage gap is greater than the wage gap after K-mobility at a given $r$ (i.e., $\hat{r}=0$ ).

Wage gap before capital mobility reform is given by: -

$$
\left(\widehat{w}_{s}-\widehat{w}\right)=\frac{\widehat{\bar{K}}}{|\Delta|}\left(\theta_{K Y} \theta_{L X}-\theta_{K X} \theta_{S Y}\right)-\frac{\widehat{t} T}{|\Delta|}\left(\theta_{K Y} \lambda_{K X} \sigma_{X}+\sigma_{Y} \lambda_{K Y} \theta_{K Y}+A \theta_{S Y}\right)
$$

And wage gap after K-mobility at given $\mathrm{r}$ is given by: -

$$
\left(\widehat{w}_{s}-\widehat{w}\right)=-\frac{\widehat{t} T}{\theta_{L X}}
$$

Now, with $\frac{\theta_{K X}}{\theta_{L X}}=\frac{\theta_{K Y}}{\theta_{S Y}}$, for same drop in $\mathrm{t}$ in the specific factor model, wage gap rises more when $r$ drops as can be seen that wage gap in (8) is greater than wage gap in (9).

Let's now take the case when sector $\mathrm{X}$ i.e., unskilled sector is $\mathrm{K}$-intensive. In that case, from Lemma 1, it follows that wage-gap will fall if K-market reforms are undertaken first. Then, further lowering of tariffs will lead to rise in rise in wage gap (see Lemma 2). The net impact on wage gap will depend on which effect is stronger. Similarly, trade-reforms undertaken first will increase the wage gap first and then due to capital market reforms wage gap will decrease. Hence, in this case, sequencing of reforms matter for the way wage gap increases as well as for the magnitude.

Further, it is important to note that if the imports are skilled-labor intensive and exports are unskilled-labor intensive, then inequality must go down with trade reforms i.e. (drop in t) and with capital account reforms i.e. (drop in r), the inequality will go up further if the skilled sector is K-intensive. This means that with trade reforms followed by capital account reforms, the inequality first goes down and then goes up. However, if capital account reforms are undertaken first followed by trade reforms, then the inequality first goes up and then goes down.

With a different trade pattern, the sequence led by trade reform will increase inequality and then capital market reform will increase it further. The same will be the pattern when capital market reform leads the sequence. Therefore, trade pattern does matter.

It is also recognized that in the short run when $\mathrm{K}$ is sector specific, the capital returns in the two sectors won't be the same. International K mobility cannot be modelled, unless we assume that $\mathrm{Kx}$ and $\mathrm{Ky}$ both can be made mobile and their return 
drops, so we have the same result. And in fact, still if skilled sector is K-intensive compared to unskilled sector, then wage gap will rise. Decline in tariff will reduce return to $\mathrm{L}$ and $\mathrm{K}$ in the unskilled sector and will raise $w_{s}$ and return to $\mathrm{K}$ in the skilled sector, does not matter if $\mathrm{K}$ is mobile within sectors. Wage gap rises. So, in this case also, if we have the $\mathrm{K}$ intensity ranking as before wage Gap will rise, sequencing does not matter.

\section{Robustness Checks}

That sequencing does not matter for the wage gap when skilled sector is $\mathrm{K}$ intensive and magnitude matters, to show that it is not a consequence of the specifics of the model we have chosen. Let us try to show that through alternative specifications.

\subsection{No Intermediate Good}

Suppose $M$ does not exist and it is a pure specific factor (SF) model (Refer Appendix $\mathrm{B}$ for detailed equations). Capital market reform will raise the wage gap if $\mathrm{Y}$ is K-intensive. Afterwards with lowered tariff at a given $\mathrm{r}$ reduces unskilled wage and skilled wage does not change. So, wage gap increases at both stages.

When trade reform takes place, due to specific factor structure $\mathrm{w}$ falls, $\mathrm{r}$ falls and $w_{s}$ goes up. Wage gap rises. Then for the next stage of reform as $r$ drops, wage gap again rises. Again, the specific factor outcome on the wage gap will be different from when $r$ is held fixed at the international level.

Nothing changes without $\mathrm{M}$ except that there is no direct boost to $w_{s}$ when $\mathrm{t}$ drops. But that's the magnitude aspect of the impact.

Suppose for arguments sake that $\mathrm{M}$ is used in $\mathrm{X}$. Then entire exercise has to be done in terms of effective rates of protection and lower effective rate in $\mathrm{X}$ will give the same result. Thus, our results are more general than what the benchmark model suggests.

\subsection{Other Sectors}

Many developing countries are characterized by agriculture which uses unskilled labor and land. Adding such a sector will not change the results at all. Suppose there is a sector using land and unskilled labor producing an output A (Refer Appendix $\mathrm{C}$ for detailed Equation). It is also assumed that $\mathrm{A}$ is an export Good. This kind of trade pattern could be seen in India where $\mathrm{Y}$ is the service sector and $\mathrm{A}$ and $\mathrm{Y}$ are agriculture and service exports. For such kind of trade pattern, one may look at work of Marjit et al. (2007a) and Beladi and Marjit (1992).

Now, capital market reform will mean a rise in wage gap, though w will rise and $\mathrm{R}$, the rent on land will fall. $w_{s} / \mathrm{w}$ rises with the same intensity assumption (Refer Appendix $\mathrm{C}$ for mathematical calculations). Tariff decline will give the expected result, so is reversing sequencing of reform. Only $\mathrm{R}$ will adjust and A will adjust, but impact on the wage gap remains the same. 
If we go for only trade liberalization $(\mathrm{t}<0)$, we may not need capital account liberalization as $r$ may drop up to international level. But even when there is no trade liberalization $(\mathrm{t}=0)$, it may not be equalized as in the specific factor model even if two countries face the same commodity prices, factor prices may not be equalized because of endowment effects. Hence, there is a scope for capital account reforms. However, with capital-account reforms (i.e., drop in r), there is a need for trade liberalization (drop in $\mathrm{t}$ ) as unskilled-sector will expand with fall in $\mathrm{r}$ and imports will fall further.

\subsection{HOS Type Structure}

Our results can easily hold even if skilled labor and unskilled labor are allowed to move between sectors and we have a HOS structure. But now we have three factors in each sector. Suppose free capital movement is allowed to peg r. Given tariff, this will mean $\mathrm{X}$ and $\mathrm{Y}$ both will be more profitable. But if $\mathrm{Y}$, the skill intensive sector uses K more intensively, it saves costs more. It will lead to rise in skilled-unskilled wage gap via Stolper Samuelson theorem. Then, if $\mathrm{X}$ is unskilled labor intensive, liberal trade policy must increase the wage gap again via Stolper Samuelson theorem as $\mathrm{X}$ is less profitable and $\mathrm{Y}$ is more profitable.

Now, suppose tariff comes down first and the $\mathrm{K}$ movement takes place later. Again, by the Stolper Samuelson theorem, $\mathrm{X}$ will be less profitable and $\mathrm{Y}$ will be more profitable. In this case also if $\mathrm{X}$ is highly unskilled labor intensive, $\mathrm{w}$ should fall and $\mathrm{Y}$ being highly skilled intensive, $w_{s}$ must rise. The specific factor model is the limiting case with 0 input/output coefficients and close to that limit the same result will hold. Wage gap will rise further when $r$ comes down as argued above.

Thus, if $\mathrm{X}$ is Unskilled labor intensive (that is why we continue to call it the unskilled sector) and the skilled sector saves capital cost more from a drop in $\mathrm{r}$, our result continues to hold when $\mathrm{S}$ and $\mathrm{L}$ both are used in these sectors. Since it is basically closer to HOS model, the Stolper Samuelson result becomes relevant.

\section{Conclusion}

We examined the impact of trade and capital account liberalization on wage inequality in a small open economy with intermediate goods. Our findings suggest that the wage gap always increases irrespective of the sequencing of external reforms if the skilled sector is capital-intensive. However, the impact of these reforms is ambiguous when the unskilled sector is more capital intensive than the skilled sector.

It is likely that global protectionism would prevail post covid-19 pandemic but capital inflow will be relatively free. The increasing protectionism would help in reducing the skilled-unskilled wage gap whereas the wage gap would increase in an economy due to the capital-intensive skilled sectors like software services, machinery and equipment etc. In addition, it is important to note that the intermediate imports are also less likely to face a higher import tariff due to the ongoing supply chain disruptions due to covid-19 pandemic for various inputs. It will further increase the wage gap thereby 
supporting the capital-intensive type skilled sectors. In the past, many developing economies have gone for different trade and capital account restrictions, and period of external reforms have opened both avenues for such economies but now a mixed bag of outcomes is likely to emerge which will be the subject of discussion of our future work.

\section{Appendix}

\section{A. Model 1}

The comparative static equations obtained for the Model 1 are as follows:

$$
\begin{gathered}
\theta_{L X} \widehat{w}+\theta_{K X} \widehat{r}=T \widehat{t} \\
\theta_{S Y} \widehat{w}_{S}+\theta_{K Y} \widehat{r}+\theta_{M Y} \widehat{t} T=0 \\
\widehat{X}=-\widehat{a}_{L X}=\theta_{K X} \sigma_{X}(\widehat{w}-\widehat{r}) \\
\hat{Y}+\widehat{a}_{S Y}=0 \\
\lambda_{K X} \widehat{X}+\lambda_{K X} \widehat{a}_{K X}+\lambda_{K Y} \widehat{Y}+\lambda_{K Y} \widehat{a}_{K Y}=\widehat{\bar{K}} \\
\lambda_{M Y} \hat{Y}=\widehat{M}^{*}
\end{gathered}
$$

Substituting $\widehat{Y}=-\widehat{a}_{S Y}$ from Eq. (13) into Eq. (15), we get,

$$
-\widehat{a}_{S Y} \lambda_{M Y}=\widehat{M}^{*}
$$

Further using definition of elasticity between two factors in a sector and Subsituting $\widehat{a}_{S Y}=-\frac{\theta_{K Y} \sigma_{Y}^{S K}\left(\widehat{w}_{s}-\widehat{r}\right)}{\left(\theta_{S Y}+\theta_{K Y}\right)}$ into the above equation, we get,

$$
\begin{gathered}
B \widehat{w}_{s}-B \widehat{r}-\widehat{M}^{*}=0 \\
\text { where, } B=\frac{\lambda_{M Y} \theta_{K Y} \sigma_{Y}^{S K}}{\left(\theta_{S Y}+\theta_{K Y}\right)}>0
\end{gathered}
$$

Substituting $\widehat{Y}$ from Eq. (13) and $\widehat{X}$ from Eq. (12) into Eq. (14) and again using definition of elasticity, we get,

$$
\begin{gathered}
\lambda_{K X} \sigma_{X} \widehat{w}-A \widehat{r}+\sigma_{Y}^{S K} \lambda_{K Y} \widehat{w}_{s}=\widehat{\bar{K}} \\
\text { where } A=\left(\lambda_{K X} \sigma_{X}+\sigma_{Y}^{S K} \lambda_{K Y}\right)>0
\end{gathered}
$$


Then, using cramer's rule, we solve the Eqs. (10), (11), (16) and (17) as follows:

$$
\left(\begin{array}{cccc}
\theta_{L X} & \theta_{K X} & 0 & 0 \\
0 & \theta_{K Y} & \theta_{S Y} & 0 \\
\lambda_{K X} \sigma_{X} & -A & \sigma_{Y}^{S K} \lambda_{K Y} & 0 \\
0 & -B & B & -1
\end{array}\right)\left(\begin{array}{c}
\widehat{w} \\
\widehat{r} \\
\widehat{w}_{s} \\
\widehat{M}^{*}
\end{array}\right)=\left(\begin{array}{c}
\widehat{T t} \\
-\theta_{M Y} \widehat{t T} \\
\widehat{\widehat{K}} \\
0
\end{array}\right)
$$

We get,

$$
\begin{gathered}
|\Delta|=\left|\begin{array}{cccc}
\theta_{L X} & \theta_{K X} & 0 & 0 \\
0 & \theta_{K Y} & \theta_{S Y} & 0 \\
\lambda_{K X} \sigma_{X} & -A & \sigma_{Y}^{S K} \lambda_{K Y} & 0 \\
0 & -B & B & -1
\end{array}\right|=-\theta_{L X}\left[\theta_{K Y} \sigma_{Y}^{S K} \lambda_{K Y}+\theta_{S Y} A\right]-\lambda_{K X} \sigma_{X} \theta_{S Y} \theta_{K X}<0 \\
\left(\widehat{w}_{s}-\widehat{w}\right)=\frac{\widehat{\bar{K}}}{|\Delta|}\left(\theta_{K X} \theta_{S Y}-\theta_{K Y} \theta_{L X}\right)+\frac{\widehat{t} T}{|\Delta|}\left(\lambda_{K X} \sigma_{X}+\sigma_{Y}^{S K} \lambda_{K Y}\right)
\end{gathered}
$$

\section{B. Model in absence of Intermediate Good(M)}

When $\mathrm{M}$ does not exist and it is a pure specific factor model, then the comparative static equations obtained for the model are as follows: -

$$
\begin{gathered}
\theta_{L X} \widehat{w}+\theta_{K X} \widehat{r}=T \widehat{t} \\
\theta_{S Y} \widehat{w}_{s}+\theta_{K Y} \widehat{r}=0 \\
\widehat{X}=-\widehat{a}_{L X}=\theta_{K X} \sigma_{X}(\widehat{w}-\widehat{r}) \\
\widehat{Y}=-\hat{a}_{S Y}=\theta_{K Y} \sigma_{Y}\left(\widehat{w}_{s}-\widehat{r}\right) \\
\lambda_{K X} \hat{X}+\lambda_{K X} \hat{a}_{K X}+\lambda_{K Y} \widehat{Y}+\lambda_{K Y} \widehat{a}_{K Y}=\hat{\bar{K}}
\end{gathered}
$$

Substituting $\widehat{Y}$ from Eq. (21) and $\widehat{X}$ from Eq. (20) into Eq. (22) and again using definition of elasticity, we get,

$$
\begin{gathered}
\lambda_{K X} \sigma_{X} \widehat{w}-A \widehat{r}+\sigma_{Y} \lambda_{K Y} \widehat{w}_{s}=\widehat{\bar{K}} \\
\text { where } A=\left(\lambda_{K X} \sigma_{X}+\sigma_{Y} \lambda_{K Y}\right)>0
\end{gathered}
$$

Then, using cramer's rule, we solve the Eqs. (18), (19), (22) and get the expression for wage gap as follows:- 


$$
\left(\widehat{w}_{s}-\widehat{w}\right)=\frac{\hat{\bar{K}}}{|\Delta|}\left(\theta_{K Y} \theta_{L X}-\theta_{K X} \theta_{S Y}\right)-\frac{\hat{t} T}{|\Delta|}\left(\theta_{K Y} \lambda_{K X} \sigma_{X}+\sigma_{Y} \lambda_{K Y} \theta_{K Y}+A \theta_{S Y}\right)
$$

where, $|\Delta|=\theta_{L X}\left[\theta_{K Y} \sigma_{Y} \lambda_{K Y}+\theta_{S Y} A\right]+\lambda_{K X} \sigma_{X} \theta_{S Y} \theta_{K X}>0$.

Now, with capital market reform $(\hat{\bar{K}}>0)$, the skilled-unskilled wage gap will increase if the sector $\mathrm{Y}$ is capital intensive. Further, with lowered tariffs at a given r; we have $\widehat{w}=\frac{1}{\theta_{L X}} T \hat{t}$ and $\widehat{w}_{s}=0$ indicating:-

$$
\left(\widehat{w}_{s}-\widehat{w}\right)=-\frac{1}{\theta_{L X}} T \widehat{t}
$$

It implies that with $\hat{t}<0$, wage gap rises.

\section{Model with Other Sectors}

The commodity price equation and full employment condition for agriculture sector A can be written as follows

$$
\begin{gathered}
a_{L A} w+a_{T A} R=\overline{P_{A}} \\
a_{T A} A=\bar{T}
\end{gathered}
$$

where, $\mathrm{R}$ is the rent on land, $\bar{T}$ is the endowment of land and $\overline{P_{A}}$ is the world price of good A.

The comparative static equation for the above sector A commodity price equation and full employment equation for agriculture sector can be written as follows: -

$$
\begin{gathered}
\theta_{L A} \widehat{w}+\theta_{T A} \widehat{R}=0 \\
\lambda_{T A} \widehat{A}+\lambda_{T A} \widehat{a}_{T A}=\widehat{\bar{T}}=0
\end{gathered}
$$

Substituting $\widehat{a}_{T A}=\theta_{L A} \sigma_{A}(\widehat{w}-\widehat{R})$ in (27) we get,

$$
\lambda_{T A} \widehat{A}+\lambda_{T A} \sigma_{A} \theta_{L A} \widehat{w}-\lambda_{T A} \theta_{L A} \sigma_{A} \widehat{R}=0
$$

Again, Solving the comparative static equations in this case using cramer's Rule, we get the following expression for skilled-unskilled wage inequality:

$$
\begin{aligned}
\left(\widehat{w}_{s}-\widehat{w}\right) & =\frac{\theta_{T A} \widehat{\hat{K}}}{|\Delta|}\left(\theta_{K X} \theta_{S Y}-\theta_{K Y} \theta_{L X}\right) \\
& +\frac{\theta_{T A} \hat{t} T}{|\Delta|}\left[\left(\lambda_{K X} \sigma_{X}+\sigma_{Y} \lambda_{K Y}\right)\left(\theta_{K X} \theta_{M Y}+\theta_{K Y}\right)\right. \\
& \left.+\left(\theta_{M Y} \theta_{L X}+\theta_{S Y}\right)\right] \quad \bar{K}
\end{aligned}
$$

Now, with capital reforms i.e. $\bar{K}>0$ and not trade reforms $(\hat{t}=0)$, we have: 


$$
\left(\widehat{w}_{s}-\widehat{w}\right)>0 \text { if } \frac{\theta_{K Y}}{\theta_{S Y}}>\frac{\theta_{K X}}{\theta_{L X}}
$$

Whereas $\left(\widehat{w_{s}}-\widehat{w}\right)<0$ if $\frac{\theta_{K X}}{\theta_{L X}}>\frac{\theta_{K Y}}{\theta_{S Y}}$. Since $|\Delta|<0$.

Similarly, with trade reforms $(\hat{t}<0)$, then $\left(\widehat{w}_{s}-\widehat{w}\right)>0$ always.

So, it can be seen that we get the same results as in our first model even with the addition of sector $\mathrm{A}$ that sequencing does not matter if skilled sector is capital intensive. In the case when unskilled sector is capital intensive then the sequencing does matter for the wage gap as well as magnitude.

Acknowledgements The authors would like to thank two anonymous referees for their valuable comments and suggestions. The usual disclaimer applies.

Funding Not applicable.

Data Availability Not applicable.

Code Availability Not applicable.

\section{Declarations}

Conflicts of Interest Not applicable.

\section{References}

Anwar S (2013) Outsourcing and the skilled-unskilled wage gap. Econ Lett 118:347-350

Beladi H, Marjit S (1992) Foreign Capital and Protectionism. The Canadian Journal of Economics 25:233-238

Brambilla I, Lederman D, Porto G (2012) Exports, export destinations, and skills. American Economic Review 102:3406-3438

Bruno M (1985) Liberalization and Stabilization in the Southern Cone of Latin America: The Reforms and Macroeconomic Adjustments. World Dev 13:867-869

Burstein A, Vogel J (2017) International trade, technology, and the skill premium. J Polit Econ. https:// doi.org/10.1086/69337

Chaudhuri S, Marjit S (2017) International trade and quality of labour. Int Rev Econ Financ 49:582-595

Das GG, Marjit S, Kar M (2020) The Impact of Immigration on Skills, Innovation and Wages: Education Matters more than where People Come from. J Policy Model 42:557-582

Diaz-Alejandro CF (1981).Southern Cone Stabilization Plans. In: Cline W and Weintraub S, eds. Economic Stabilization in Developing Countries. The Brookings Institutions, Washington, DC

Dinopoulos E, Syropoulos C, Xu B, Yotov YV (2011) Intraindustry trade and the skill premium: Theory and evidence. J Int Econ 84(1):15-25

Edwards S (1984) The Order of Liberalization of the External Sector in Developing Countries. Essays in International Finance, no. 156, December.

Feenstra, R. C. \& Hanson,G. H.(1995) "Foreign Direct Investment and Relative Wages: Evidence from Mexico's Maquiladoras," NBER Working Papers 5122, National Bureau of Economic Research, Inc.

Furceri D, Loungani P (2015) Capital Account Liberalization and Inequality, IMF Working paper no. $\mathrm{WP} / 15 / 243$

Goldberg P, Pavcnik N (2007) Distributional effects of globalization in developing countries. Journal of Economic Literature 45:39-82

Hellier J (2019) Phases of Globalization, Wages and Inequality. Open Econ Rev 30:905-931 
Jones RW (1965) The Structure of Simple General Equilibrium Models. J Polit Econ 73:557-572

Jones RW (1971) A three-factor model in theory, trade and history in J. Bhagwati et al (eds.), Trade, balance of payments and growth, pp 3-21, North-Holland: Amsterdam

Larrain M (2015) Capital Account Opening and Wage Inequality. Review of Financial Studies 28:1555-1587

Lundberg M, Squire L (2003) The simultaneous evolution of growth and inequality. Economic Journal 113

Mandal B, Prasad AS (2019) "A Note on wage inequality due to trade reform, capital inflow, bureaucratic reform and time zone difference", Unpublished manuscript.

Marjit S, Kar S, Acharyya R (2007a) Agricultural prospects and informal wage in general equilibrium. Econ Model 24:380-385

Marjit S, Acharyya R (2003) Trade and Wage-Inequality in Developing Countries: A Simple General Equilibrium Approach. Physica/Springer Verlag, Heidelberg

Marjit S, Kar S (2019) International Capital Flows, Land Conversion and Wage Inequality in Poor Countries. Open Economies Review Springer 30:933-945

Marjit S, Kar S (2005) Emigration and Wage Inequality Economic Letters 88:141-145

Marjit S, Ghosh S, Biswas AK (2007b) Informality, Corruption and Trade Reform. Eur J Polit Econ 23:777-789

Marjit S, Huria S, Pant M (2020) Unskilled immigration, technical progress, and wages-Role of the household sector. Rev Int Econ 28:235-251

Matsuyama K (2007) Beyond Icebergs: Towards A Theory of Biased Globalization. Rev Econ Stud $74: 237-253$

McKinnon R (1982) The Order of Economic Liberalization: Lessons from Chile and Argentina, in K. Brunner and A. Meltzer(eds.), Economic Policy in a World of Change, North-Holland : Amsterdam.

Mishra P, Das DK (2013) Trade liberalization and wage inequality in India: a mandated wage equation approach. Indian Growth and Development Review 6:113-127

Nataraj G, Tandon A (2011) China's Changing Export Structure: A Factor-Based Analysis. Econ Pol Wkly 46:130-136

Rojas-Vallejos J, Turnovsky SJ (2017) Tariff Reduction and Income Inequality: Some Empirical Evidence. Open Econ Rev 28:603-631

Whang U (2016) Skilled-Labor Intensity Differences Across Firms, Endogenous Product Quality, and Wage Inequality. Open Econ Rev 27:251-292

Winters A, McGulloch N, McKay A (2004) Trade liberalization and poverty: the evidence so far. J Econ Lit XLII: $72-115$

Wu J-Y, Hsu C-C (2012) Foreign direct investment and income inequality: does the relationship vary with absorptive capacity? Economic Modeling 29:2183-2189

Publisher's Note Springer Nature remains neutral with regard to jurisdictional claims in published maps and institutional affiliations. 